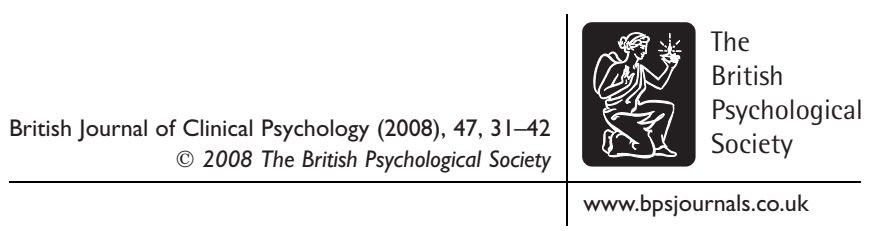

\title{
Parents grieving the loss of their child: Interdependence in coping
}

\author{
Leoniek Wijngaards-de Meij '*, Margaret Stroebe', Henk Schut', \\ Wolfgang Stroebe', Jan van den Bout', Peter G. M. van der \\ Heijden $^{2}$ and Iris Dijkstra' \\ 'Department of Psychology, Faculty of Social Sciences, Utrecht University, Utrecht, \\ The Netherlands \\ ${ }^{2}$ Department of Methodology and Statistics, Faculty of Social Sciences, Utrecht \\ University, Utrecht, The Netherlands
}

\begin{abstract}
Objectives. A longitudinal study was conducted among bereaved parents, to examine the relationship between parents' own and their partners' ways of coping in terms of the constructs loss-orientation and restoration-orientation (coping strategies based on the bereavement-specific Dual Process Model (Stroebe \& Schut, 1999)), and psychological adjustment following the death of their child.
\end{abstract}

Method. 219 couples participated at 6, 13 and 20 months post-loss. Use of the Actor Partner Interdependence Model within multi-level regression analyses enabled assessment of both actor as well as partner effects, and permitted differentiating these effects according to the gender of the parent.

Results. Loss-orientation was predictive of negative psychological adjustment, while restoration-orientation was related to better adjustment. Furthermore, high levels of restoration-oriented coping buffered the negative effect of high levels of lossorientation on depression. In the interpersonal context, results indicated that for men, having a female partner high in restoration-oriented coping was related to positive adjustment.

Conclusion. In coping with the loss of their child, intra-personal as well as interpersonal processes are relevant for the adjustment process of parents after the loss of their child.

The loss of a child is a devastating event that severely disrupts the lives of those affected for years thereafter (for a review see Rubin \& Malkinson, 2001). In Western society, the death of a child has generally been found to elicit more intense and complicated grief reactions than other types of bereavement (Sanders, 1989). Substantial psychological and physical

* Correspondence should be addressed to Leoniek Wijngaards-de Meij, Department of Psychology, Faculty of Social Sciences, Utrecht University, PO Box 80 I40, 3508 TC Utrecht, The Netherlands (e-mail: I.wijngaards@uu.nl). 


\section{Leoniek Wijngaards-de Meij et al.}

health consequences for the parents have been established, including an increased risk of mortality (Li, Precht, Mortensen, \& Olsen, 2003). The situation of parental bereavement can be complicated by the fact that not only have both parents lost their child, but the person to whom they would probably turn in stressful situations, may be too distressed to provide support. There may also be differences between partners in the ways they cope with their loss (e.g. in the need to talk about the deceased child) which may add to individual distress and marital disruption (Dijkstra \& Stroebe, 1998).

The coping literature in general, and in bereavement specifically, has largely focused on individual aspects of coping without considering the interpersonal context in which grieving occurs. Research in other areas has begun to explore how differences in the way that partners cope affect their psychological well-being, for example, how couples together face the chronic illness of one of the partners (Badr, 2004). Whereas the cognitive stress theory of Lazarus and Folkman (1984) takes an individualistic perspective in examining how individuals are affected by their own reactions to illness, research on close relationships emphasizes the interdependence between marital partners (e.g. Lewis et al., 2006). From the interpersonal perspective, both spouses are not only affected by their own reactions but also by the way their partner copes. Accordingly, when the couple loses a child, it seems plausible that not only the coping style of the parent him or herself influences psychological adjustment after bereavement, but also the coping style of the partner may play a role in the adjustment process. Yet, to our knowledge, no research has been conducted to examine the coping style of both bereaved parents in combination, in relationship to the adjustment process after the loss of their child.

Research on gender differences in coping behaviours has shown that men and women approach problems differently. Tamres, Janicki, and Helgson (2002) conducted a meta-analysis on gender differences in coping across several stressors (including bereavement), and found that women reported greater use of most coping strategies. For example, in the bereavement context women have been found to confront their emotions more than men, while men deal with this stressful life-event by using more avoidant coping strategies (Stroebe, Stroebe, \& Schut, 2001). Gender differences have also been found in interpersonal research on stressors in general (e.g. Badr, 2004). It is, therefore, important to examine whether individual and interpersonal effects are the same for men and women.

The limitations of general coping theories when applied to the bereavement area, such as the lack of specificity with respect to the bereavement context, led Stroebe and Schut to develop a stressor-specific model of coping with bereavement, namely the Dual Process Model (DPM). General coping theories, notably Cognitive Stress Theory (Lazarus \& Folkman, 1984), do not accommodate for multiple stressors simultaneously, whereas in bereavement there is a need to oscillate between primary stressors to do with the loss itself and secondary stressors to do with changes that occur as a consequence of the loss (for more details see Stroebe \& Schut, 1999). Although it is not the purpose of our study to investigate the parameters of the DPM comprehensively, this model is nevertheless of importance to our study. The model postulates two coping strategies, loss-orientation and restoration-orientation, attention to both of which is needed for favourable psychological adjustment after bereavement. According to the DPM, loss-orientation and restoration-orientation can be both problem focused and/or emotion focused (in terms of CST). Loss-orientation refers to the concentration on, and dealing with, some aspect of the loss experience itself, most particularly, with respect to the deceased person. As such, although there is conceptual overlap, there is a clear distinction from grief symptomatology per se: loss-orientation refers to a strategy of 
coping (handling of grief) while grief symptomatology refers to emotional reactions associated with bereavement. Restoration-orientation refers to dealing with secondary sources of stress. This coping strategy incorporates focusing on changes which have come about as a result of the bereavement, and which need to be dealt with. Restoration-oriented coping was defined more specifically for this study of child loss as an active attempt to look towards the future and to rebuild one's life.

The main aim of this study was to clarify whether there is a relationship between the coping strategies of the parent and those of his or her partner, on the one hand, and the adjustment process of the parent, on the other hand. Furthermore, we wanted to ascertain whether these relationships differed by gender. Finally, although our study cannot be said to investigate all parameters of the DPM, we wanted to establish whether loss-oriented coping and restoration-oriented coping had an extra effect on the psychological adjustment of the parent when studied in combination ${ }^{2}$.

\section{Method}

\section{Design}

The design of the study was longitudinal, consisting of three points of measurement at 6 , 13 and 20 months after the death of the child. An earlier report on this study described relationships between characteristics of the parent, the child, circumstances relating to the death of the child, adult attachment dimensions and the adjustment process (see Wijngaards-de Meij et al., 2005, Wijngaards-de Meij et al., 2007).

The attrition rate was $17.8 \%$ over the 14-month period of the study. The biographical data about the parents, the child and circumstances surrounding the loss were gathered during an interview with the couple at the first measurement point after their loss. At all three moments in time, parents were asked to fill in a set of questionnaires separately.

\section{Participants}

In total 463 Dutch couples who had lost a child were contacted via obituary notices in local and national newspapers. Five and half months after the loss parents were sent a letter and were additionally called by phone to inquire about participating in the study. The study was approved by the Research Institute of Psychology and Health's ethical committee at Utrecht University. Informed consent procedures were utilized. Bereaved parents who were grandparents (i.e. those parents whose deceased child was a parent him/herself) were not included in this investigation, given that they are likely to experience additional difficulties. Single parents were also excluded, because the study was focused on individual and partner predictors of grief. In total, 219 parent couples (47\%) agreed to participate. The parents who participated ranged in age from 26 to 68 years $(M=42.2, S D=9.1)$ and their deceased child's age ranged from stillborn to 29 years with a mean age of 10.2 years $(S D=9.8)$. A total of $68.7 \%$ of the deceased children were boys. The causes of death varied from neonatal death or stillborn (16.3\%), through illness or disorder (47.7\%), to accident, SIDS, suicide or homicide (36.1\%).

\section{Measurement instruments}

\section{Independent variables}

Coping with the loss was measured using a newly constructed coping list, the Dual Coping Inventory (DCI). This measure, which was theoretically based on the DPM, included two scales: Loss-orientated coping and Restoration-oriented coping. The two- 


\section{Leoniek Wijngaards-de Meij et al.}

factor model of the DCI (with the factors loss- and restoration-orientation) was tested with confirmative factor analyses, for all three moments in time, using AMOS 5.0 (Arbuckle, 2003). All the three analyses reported a good fit (NFI from .984 to .988, CFI from .991 to .994, RMSEA from .046 to .061). The loss-oriented coping scale consisted of three items: 'I am occupied with the loss of my child', (2) 'I dwell on my sorrow', (3) 'I think of our deceased child' (mean, range 1-5). The restoration-oriented coping scales included four items: (1) 'I direct my thoughts towards the future'; (2) 'Despite everything, I am trying to make the best of it'; (3) 'I try to look ahead' and (4) 'I am trying to go on with my life' (mean, range 1-5). Answers are given on a five-point scale, ranging from 'not at all'(1) to 'very much'(5). Measurement was made at three moments in time $(\mathrm{T} 1=6$ months, $\mathrm{T} 2=13$ months, $\mathrm{T} 3=20$ months after the loss $)$. Over time, Cronbach's alpha ranged from .77 to .82 for loss-orientation and from .84 to .86 for restoration-orientation.

\section{Dependent variables}

Depression was measured using the subscale of the Symptom Checklist-90 (SCL-90, Derogatis, 1977; Dutch translation by Arrindell \& Ettema, 1986). The subscale depressive symptomatology consists of 16 items. Answers are given on a five-point scale, ranging from 'not at all'(1) to 'very much'(5). In our study Cronbach's alpha ranged from .92 to .94 .

Grief reactions were measured using the Inventory of Complicated Grief (ICG, Prigerson et al., 1995; Dutch version by Dijkstra, Schut, Stroebe, Stroebe, \& van den Bout, 2000). The ICG consists of 19 items covering psychological aspects of grief, e.g. 'I find it difficult to accept the death of our child' and 'I feel that it is unfair that I should live when our child died'. The answers are given on a five-point scale ranging from 'never'(1) through 'sometimes'(3) to 'always'(5). In our study Cronbach's alpha ranged from .90 to .92 .

The dependent variables were transformed to a scale 0-100 to facilitate comparison between the predictors and between the predictive value for depression and grief. The transformation was linear and we set the lowest score equal to zero and the highest score in the dataset equal to 100.

\section{Analysis and statistical procedure}

To analyse the individual parent effect, the partner effect and possible interactions, we used the Actor Partner Interdependence Model (APIM) (Kashy \& Kenny, 2000; Kenny, Mannetti, Pierro, Livi, \& Kashy, 2002). The APIM is appropriate when the dyad (i.e. the marital couple) is the unit of analysis and tests need to be performed both within and between dyads (Kenny, 1996). Variables are assessed for both the actor and his or her marital partner. Use of the APIM then allows one to estimate not only whether an actor's own attributes predict his or her responses but also whether the attributes of the actor's partner also predict the actor's responses, while the impact of the actor's own attributes is controlled. In our study, the actor effect estimates the influence that an actor's own score on the independent variable (e.g. restoration-oriented coping) has on that person's outcome measure (e.g. depression), and the partner effect estimates the influence that the partner scores on the independent variable have on the actor's outcome (Kashy \& Kenny, 2000, Kenny et al., 2002). Not only can the actor and the partner effects of variables be tested in this model, but also several interactions involving the actor and/or partner variables. 
The Actor Partner Interdependence Model was tested, as recommended by Campbell and Kashy (2002), within a multi-level regression analysis. Besides being suitable for testing the APIM, multi-level analyses are appropriate for having several predictors in a dependent structure (Hox, 2002). A unique feature of multi-level analysis is that it works with a specific statistical model designed for nested data. In our data there is a nested structure captured by a three-level hierarchy. The three measurement moments in time are nested in one person, the father or mother. The measurements of the father and mother are dependent and are thereby nested in a couple. Therefore, time since death is the lowest level (first level), nested in the individual (second level). The parents (second level) are nested in a couple (third level). Each independent variable varies only at one specific level. Time since the loss of the child varies only at the lowest level, the time level (first level). The individual factors of the two parents differ at the individual level (second level). The remaining factors are the same for the parents in a couple, but these factors do vary between the couples at the couple level (third level).

When there are interactions included in the regression analyses, the standardized regression weights should be calculated by standardizing the independent and dependent variables (Aiken \& West, 1991). Therefore, we standardized the variables grief, depression, and loss-oriented coping and the restoration-oriented coping of both parents. In the Graphs, the unstandardized variables were used to facilitate interpretation. The standard $R^{2}$ (explained variance) cannot be calculated within multilevel regression analyses. We therefore used the procedures that are most common in multi-level research to estimate the explained variance (Hox, 2002). For each of the two dependent variables (grief and depression) a multi-level regression analysis was performed with MLwiN (Rasbash et al., 2000).

\section{Results}

\section{Descriptives}

In general, as can be seen in Table 1, husbands were less loss-oriented than wives (main effect gender, $F(1,352)=47.09, p<.05)$, and both men and women became less lossoriented through time (main effect time, $F(2,704)=29.55, p<.05$ ). The restorationorientation of men was high in the beginning, the restoration-orientation of women started lower but rose slightly through time (different linear trends for time by gender, $F(1,345)=4.38, p<.05)$.

Table I. Level of grief, depression and coping at the three time points

\begin{tabular}{|c|c|c|c|c|c|c|c|}
\hline & & \multicolumn{2}{|c|}{ TI } & \multicolumn{2}{|c|}{$\mathrm{T} 2$} & \multicolumn{2}{|c|}{ T3 } \\
\hline & & $M$ & $S D$ & $M$ & $S D$ & M & $S D$ \\
\hline \multirow[t]{2}{*}{ Grief } & Men & 40.87 & 18.90 & 39.80 & |8.0| & 36.93 & 18.33 \\
\hline & Women & 49.73 & 19.76 & 46.23 & 18.76 & 45.58 & 16.89 \\
\hline \multirow[t]{2}{*}{ Depression } & Men & 18.53 & 16.63 & 16.98 & 16.39 & $|5.6|$ & 16.10 \\
\hline & Women & 31.84 & 22.24 & 29.67 & 21.36 & 26.79 & 19.52 \\
\hline \multicolumn{8}{|l|}{ Coping } \\
\hline \multirow[t]{2}{*}{ Loss-oriented } & Men & 3.41 & 0.91 & 3.40 & 0.86 & 3.27 & 0.87 \\
\hline & Women & 4.07 & 0.73 & 3.91 & 0.75 & 3.74 & 0.75 \\
\hline \multirow[t]{2}{*}{ Rest-oriented } & Men & 3.70 & 0.89 & 3.59 & 0.81 & 3.63 & 0.83 \\
\hline & Women & 3.49 & 0.94 & 3.52 & 0.93 & 3.61 & 0.90 \\
\hline
\end{tabular}


The correlation (based on the average of the variables for all three measurement moments) between the two coping strategies was quite small ( -.23 , see Table 2$)$. Lossorientation had a moderately high correlation with both grief and depression (resp. .57 and .47). Restoration-orientated coping correlated negatively with both grief and depression (resp. -.48 and -.45 ). There were neither significant differences in the correlations between men and women, nor did the correlations differ significantly through time.

Table 2. Correlations

\begin{tabular}{lccc}
\hline & Loss-oriented & Rest-oriented & Grief \\
\hline Loss-oriented coping & 1.00 & & \\
Restoration-oriented coping & $-.23^{*}$ & 1.00 & \\
Grief & $.57^{*}$ & $-.48^{*}$ & 1.00 \\
Depression & $.47^{*}$ & $-.45^{*}$ & $.72^{*}$ \\
\hline
\end{tabular}

*Correlation is significant at the 0.01 level.

\section{Actor partner analyses: Depression}

In the first Model beside the variables time and gender, the coping strategies of the actor were introduced and, to test whether coping effects differed for men and women, interactions between gender and the coping styles were introduced (Table 3). Women reported more depressive symptoms than men and through time the level of depression decreased for both. Both the coping styles of the actor were predictors of own depression, higher levels of loss-orientation were related to higher levels of depression while higher levels of restoration-orientation were related to lower levels of depression. Of the interactions between the gender and the coping styles of the actor, only the interaction between gender and restoration-orientation was significant. Interaction effects have to be interpreted in combination with the main effects of gender and the coping style. The interaction indicated that the relationship between restoration-oriented coping and depression was different for men and women. The effect of restoration-orientation on depression was even stronger for women: the combination of being a women and being high in restoration-orientation was associated with lower levels of depression.

In Model 2, the coping strategies of the partner as well as the interactions between gender and the coping styles of the partner were introduced. There was a main effect of restoration-oriented coping and an interaction effect of restoration-oriented coping of the partner with gender. For men, the effect of the restoration-orientated coping of the partner, which in this analysis can be seen in the main effect $(\beta=-0.10, z=2.98$, $p<.05$ ), was that the more restoration-oriented his wife was, the lower the depression of the man. For women, the main effect has to be viewed in combination with the interaction between restoration-oriented coping of the partner with gender $(\beta=0.13)$ to see that the effect of partner restoration for the women was slightly the opposite $(\beta=-0.10+0.13=0.03)$. Single slope analysis (Aiken $\&$ West, 1991) revealed that this effect for women was not significant $(z=0.91, p>.05)$. Hence, when the husband had a wife who was high in restoration-orientation, he was less depressed (see Figure 1). For loss-orientation, none of the partner effects, nor any interactions between gender and the actor or gender and partner coping were significant. 
Parents grieving the loss of their child 37

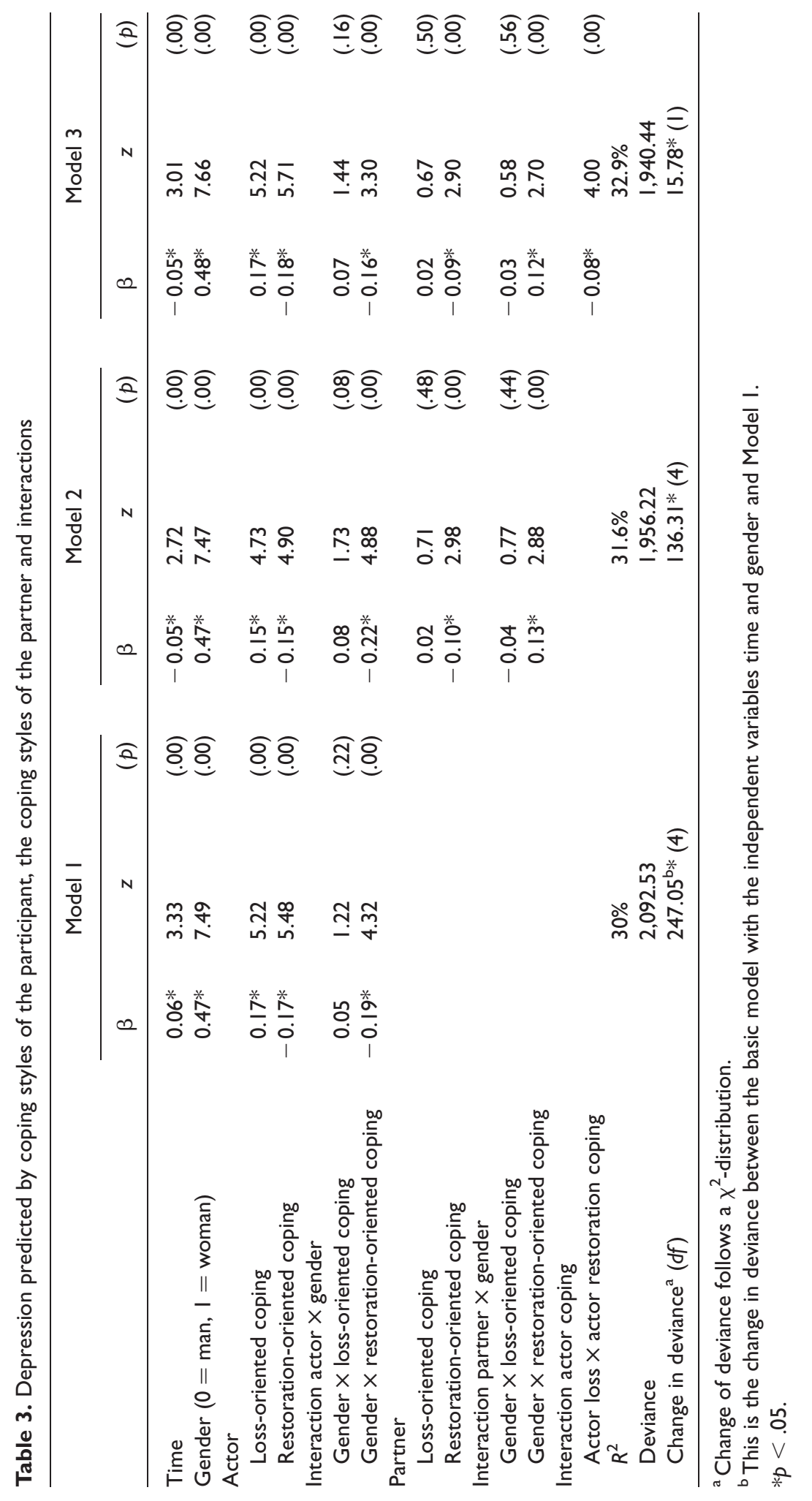




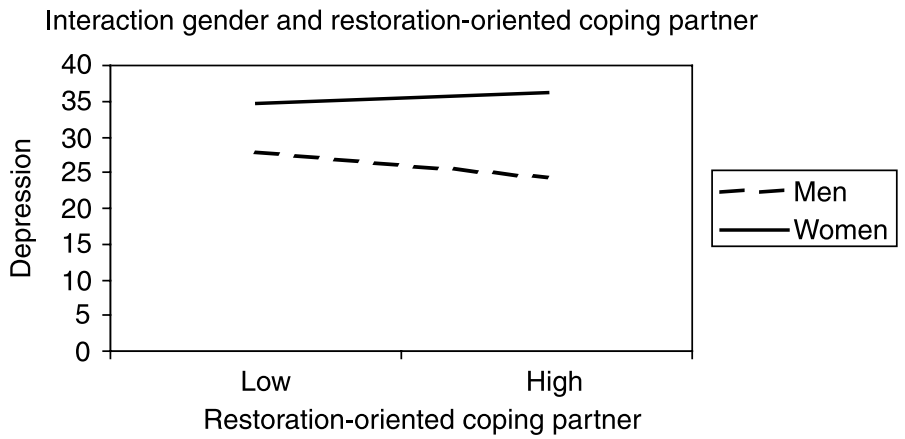

Figure I. Interaction gender and restoration-oriented coping partner.

In Model 3, the interaction between loss-oriented coping and restoration-oriented coping of the actor was tested to explore whether the effect of loss-orientation depended on the level of restoration-orientation. This interaction was significant and showed that the positive relationship between loss-oriented coping and depression (high loss-orientation related to high depression) was true for parents low in restorationorientation, but this relationship was relatively weak for parents high in restorationorientation. In other words, restoration-orientation had a buffering effect on the effect of loss-orientation (Figure 2).

\section{Actor partner analyses: Grief}

For grief, the models were built in the same order. In Model 1, there were main effects for time and gender; through time the grief symptoms decreased and women had higher levels of grief than men. As for depression, the coping styles of the actor were related to the levels of grief, higher levels of loss-orientation were related to higher levels of grief and higher levels of restoration-orientation were related to lower levels of grief. The interactions between gender and the coping styles were introduced, to test whether there were different relationships between coping and grief for men and women. There was no significant interaction, which means that the main effects of the coping styles of the actor were the same for men and women. In Model 2, it was shown that the restoration-orientation of the partner was also related to the grief of the actor. The restoration-orientation of the partner was connected to the level of grief of the actor, but this was again, as in depression, gender specific. For a husband, it was helpful if his wife

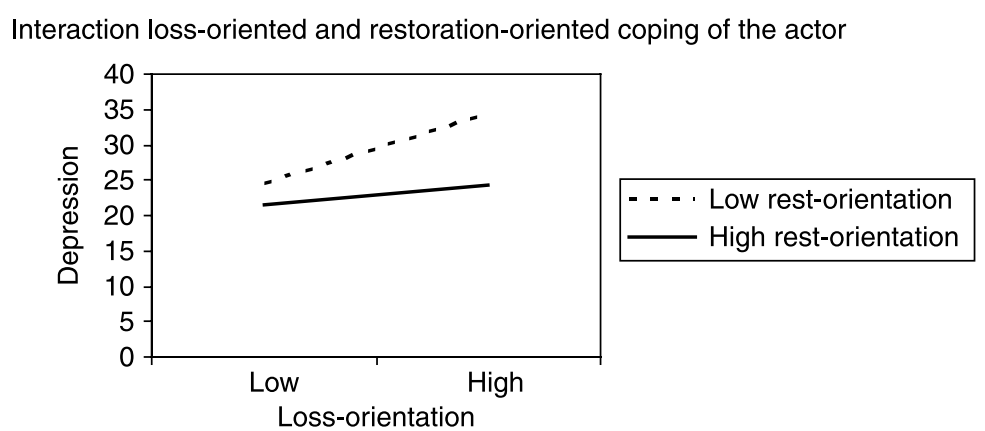

Figure 2. Interaction loss-oriented and restoration-oriented coping of the actor. 


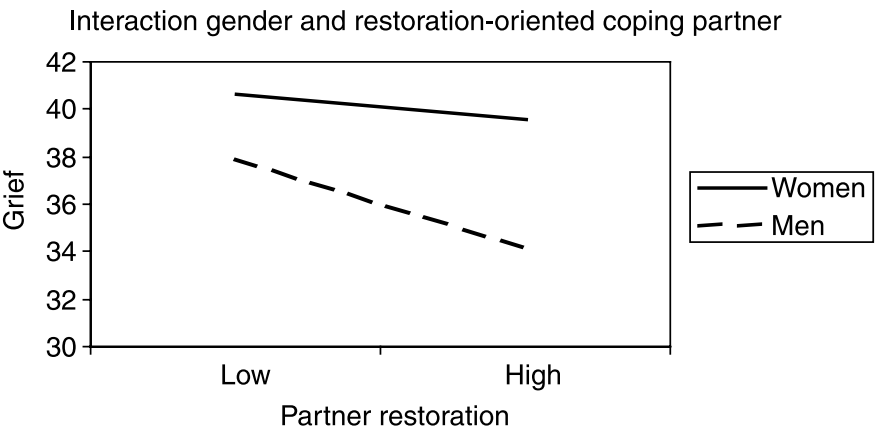

Figure 3. Interaction gender and restoration-oriented coping partner.

had high levels of restoration-orientation, because this was associated with lower levels of grief in the man $(\beta=-0.10, z=3.41, p<.05)$. A single slope analysis revealed that for a woman, the level of restoration-orientation of her husband was unrelated to her level of grief $(\beta=-0.10+0.07=-0.03, z=0.43, p>.05)$. In Model 3 , the interaction between loss-oriented coping and restoration-oriented coping of the actor was introduced, but this was not significant. For grief Model 2 is the final Model (Table 4).

\section{Discussion}

Our investigation has demonstrated the importance of studying grief and depression as an intra-personal as well as an interpersonal process ${ }^{2}$. In contrast to the few prior studies on coping strategies in bereaved parents (e.g. Murphy, Johnson, Chung, \& Lohan, 2003; Anderson, Marwit, Vanderberg, \& Chibnall, 2005), we used the Actor Partner Interdependence Model to analyse our dyadic data. This relatively new method is especially designed and the most appropriate for studying partner effects in a nested model (Kenny, Kashy, \& Cook, 2006). This method allowed us to assess the relationship between the actors' own coping strategies and their psychological adjustment as well as the possible effect of the coping strategy of their partners on the actors' adjustment. In addition, our study focused on bereavement-specific coping strategies instead of more general forms used in prior research.

Our findings show that the adjustment process for men is not only related to their own coping strategies, but also to the coping strategy of their wife. The more his wife was oriented towards rebuilding their lives after the loss (restoration-oriented coping), the lower were the levels of depression and grief of the husband. Because men were generally higher in restoration-orientation than women, this implies that when a woman engaged in a strategy that was generally more often used by men (i.e. coping in a way more similar to the men) this was beneficial for the husband. For women, the way of coping of their husbands was neither related to their depression nor their grief scores. This could be due to the fact that women were more loss-oriented. Loss-oriented coping does not need to involve the partner, because feelings and action are centred around the relation between the parent and the child. In contrast, partner involvement might be important in restoration-oriented coping. It might be difficult for a couple to rebuild their lives after a loss, if one of the partners remains preoccupied with the loss and unmotivated to look towards the future. 
40 Leoniek Wijngaards-de Meij et al.

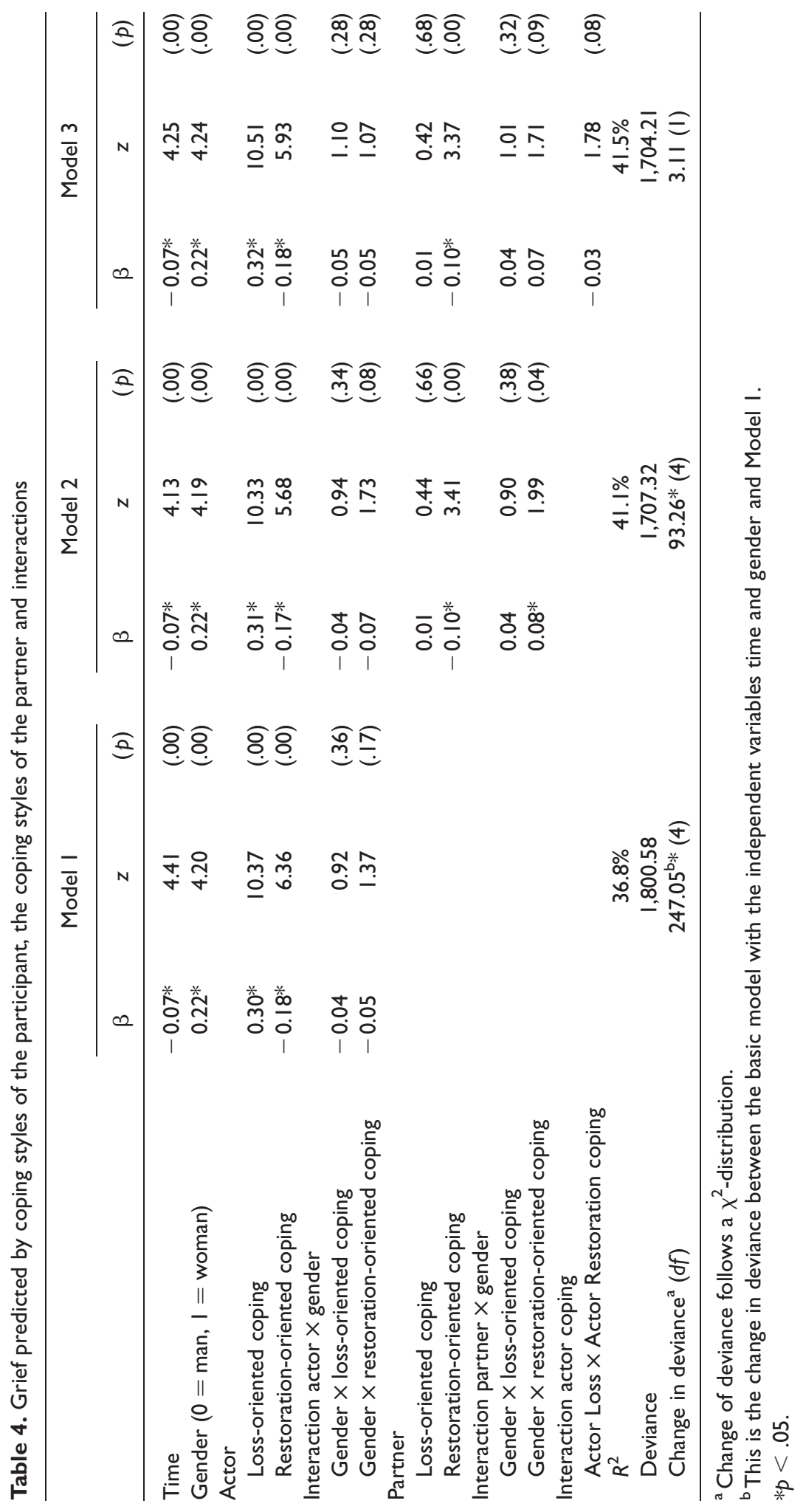


However, being high in loss-orientation is not necessarily associated with high levels of depression, as long as the loss-orientation is accompanied by high levels of restoration-orientation. Although, we could not assess whether individuals oscillated between these two coping strategies, these results are partly in line with the DPM reasoning that the combination of both coping strategies is beneficial for the adjustment process. One finding that appears to be inconsistent with the DPM is that bereaved parents who were high on restoration-orientation and low on loss-orientation, had low scores on depression. A potential explanation for this pattern could be that these parents had already gone through a period of severe loss-orientation and were now focusing more on moving on with their lives. Another unexpected pattern is that the interaction of restoration-oriented coping and loss-oriented coping was not found for grief symptomatology (although a trend was found). It is not easy to explain this finding. These results suggest the need for more research investigating parameters of the DPM.

There are some limitations to our study. First, because no valid scales of specific bereavement coping behaviour were available, we had to develop a new measure. However, our scales are theoretically based on the Dual Process Model (Stroebe \& Schut, 1999) and had good psychometric properties. A further concern is a potential conceptual overlap between loss-orientated coping and grief symptoms. For the purpose of examining interpersonal influences on individual grieving this is, however, less of a problem (e.g. because we look at the relationship of the loss-orientation of one parent with the grief of the partner).

The results of our study also have potentially important clinical implications. Within the couple that experienced a bereavement, the restoration-orientation of the women appears to be a crucial factor in the adjustment process, because women high on restoration-oriented coping were doing better themselves ('compensating' for being high in loss-orientation) and had partners who were less depressed. An important next step would be to identify the processes underlying high restoration-orientation in women. Although our study was done within the bereavement area, future research is needed to examine whether these connections are also found for other stressful situations.

\section{References}

Aiken, L. S., \& West, S. G. (1991). Multiple regression: Testing and interpreting interactions. London: Sage publications.

Anderson, M. J., Marwit, S. J., Vanderberg, B., \& Chibnall, J. T. (2005). Psychological and religious coping strategies of mothers bereaved by the sudden death of a child. Death Studies, 29, 811-826.

Arbuckle, J. L. (2003). Amos 5.0 update to the AMOS user's guide. Chicago, IL: Smallwaters.

Arrindell, W. A., \& Ettema, J. H. M. (1986). SCL-90: Handleiding bij een multidimensionele psychopathologie-indicator. Lisse, The Netherlands: Swets and Zeitlinger.

Badr, H. (2004). Coping in marital dyads: A contextual perspective on the role of gender and health. Personal Relationships, 11, 197-211.

Campbell, L., \& Kashy, D. A. (2002). Estimating actor, partner, and interaction effects for dyadic data using, PROC MIXED and HLM: A user-friendly guide. Personal Relationships, 9, 327-342.

Derogatis, L. R. (1977). SCL-90: Administration, scoring and procedures manual-I for The R(evised) version. Baltimore: John Hopkins University School of Medicine.

Dijkstra, I. C., Schut, H., Stroebe, M., Stroebe, W., \& Van den Bout, J. (2000). Inventory of Complicated Grief, Dutch translation. In I. C. Dijkstra (Ed.), Living with loss: Parents grieving for the death of their child (Appendix A) (p.233). Enschede: Febodruk. 
42 Leoniek Wijngaards-de Meij et al.

Dijkstra, I. C., \& Stroebe, M. S. (1998). The impact of a child's death on parents: A myth (not yet) disproved? Journal of Family Studies, 4, 159-185.

Hox, J. (2002). Multilevel analysis: Techniques and applications. Mahwah, NJ: Erlbaum.

Kashy, D. A., \& Kenny, D. A. (2000). The analysis of data from dyads and groups. In H. T. Reis \& C. M. Judd (Eds.), Handbook of research methods in social and personality psychology (pp. 451-477). New York: Cambridge University Press.

Kenny, D. A. (1996). Models of non-independence in dyadic research. Journal of Social and Personal Relationships, 13, 279-294.

Kenny, D. A., Kashy, D. A., \& Cook, W. L. (2006). Dyadic data analysis. New York: The Guilford Press.

Kenny, D. A., Mannetti, L., Pierro, A., Livi, S., \& Kashy, D. A. (2002). The statistical analysis of data from small groups. Journal of Personality and Social Psychology, 83, 126-137.

Lazarus, R. S., \& Folkman, S. (1984). Stress, appraisal, and coping. New York: Springer.

Lewis, M. A., McBride, C. M., Pollak, K. I., Puleo, El, Butterfiels, R. M., \& Emmons, K. M. (2006). Understanding health behaviour change among couples: An interdependence and communal coping approach. Social Science and Medicine, 62, 1369-1380.

Li, J., Precht, D., Mortensen, P., \& Olsen, J. (2003). Mortality in parents after death of a child in Denmark: A nationwide follow-up study. Lancet, 361, 363-367.

Murphy, S. A., Johnson, L. C., Chung, I.-J., \& Beaton, R. D. (2003). The prevalence of PTSD following the violent death of a child and predictors of change 5 years later. Journal of Traumatic Stress, 16, 17-25.

Prigerson, H. G., Maciejewski, P. K., Reynolds, C. F., Bierhals, A. J., Newsom, J. T., \& Fasiczka, A. (1995). Inventory of Complicated Grief: A scale to measure maladaptive symptoms of loss. Psychiatry Research, 59, 65-79.

Rasbash, J., Browne, W., Goldstein, H., Yang, M., Plewis, I., \& Healy, M. (2000). A user's guide to MLwiN. University of London: Multilevel Models Project.

Rubin, S. S., \& Malkinson, R. (2001). Parental response to child loss across the life cycle: Clinical and research perspectives. In M. S. Stroebe, R. O. Hansson, W. Stroebe, \& H. Schut (Eds.), Handbook of bereavement research: Consequences, coping, and care (pp.219-240). Washington, DC: Psychological Association Press.

Sanders, C. M. (1989). Grief: The mourning after: Dealing with adult bereavement. Oxford, England: Wiley.

Stroebe, M., \& Schut, H. (1999). The Dual Process Model of coping with bereavement: Rationale and description. Death Studies, 23, 197-224.

Stroebe, M., Stroebe, W., \& Schut, H. (2001). Gender differences in adjustment to bereavement: An empirical and theoretical review. Review of General Psychology, 5, 62-83.

Tamres, L. K., Janicki, D., \& Helgeson, V. S. (2002). Sex differences in coping behaviour: A metaanalytic review and an examinations of relative coping. Personality and Social Psychology Review, 6, 2-30.

Wijngaards-de Meij, L., Stroebe, M., Schut, H., Stroebe, W., van den Bout, J., van der Heijden, P., et al. (2005). Couples at risk following the death of their child: Predictors of grief versus depression. Journal of Consulting and Clinical Psychology, 73, 617-623.

Wijngaards-de Meij, L., Stroebe, M., Schut, H., Stroebe, W., van den Bout, J., van der Heijden, P., et al. (2007). Patterns of attachment and parents' adjustment to the death of their child. Personality and Social Psychology Bulletin, 33, 537-548.

Received 2 I July 2006; revised version received 4 May 2007 